\title{
Long-term clinical outcome in nasopharyngeal carcinoma patients with post-radiation persistently detectable plasma EBV DNA
}

\author{
Wen-Yi Wang1,2,*, Tian-Yun Lin ${ }^{3, *}$, Chih-Wen Twu ${ }^{4,5}$, Hsiao-Hui Tsou ${ }^{6,7}$, Po-Ju Lin ${ }^{8}$, \\ Yi-Chun Liu' ${ }^{8}$, Jing-Wen Huang ${ }^{8}$, He-Yuan Hsieh ${ }^{8}$, Jin-Ching Lin ${ }^{5,8,9,10}$ \\ ${ }^{1}$ Department of Nursing, Hung Kuang University, Taichung, Taiwan \\ ${ }^{2}$ Department of Nursing, National Taichung University of Science and Technology, Taichung, Taiwan \\ ${ }^{3}$ Department of Otorhinolaryngology, Taipei Veterans General Hospital, Taipei, Taiwan \\ ${ }^{4}$ Department of Otorhinolaryngology, Taichung Veterans General Hospital, Taichung, Taiwan \\ ${ }^{5}$ Faculty of Medicine, School of Medicine, National Yang-Ming University, Taipei, Taiwan \\ ${ }^{6}$ Institute of Population Health Sciences, National Health Research Institutes, Miaoli, Taiwan \\ ${ }^{7}$ Graduate Institute of Biostatistics, College of Public Health, China Medical University, Taichung, Taiwan \\ ${ }^{8}$ Department of Radiation Oncology, Taichung Veterans General Hospital, Taichung, Taiwan \\ ${ }^{9}$ Institute of Clinical Medicine,School of Medicine, National Yang Ming University, Taipei, Taiwan \\ ${ }^{10}$ Department of Medicine, China Medical University, Taichung, Taiwan \\ *These authors contributed equally to this work
}

Correspondence to: Jin-Ching Lin, email: jclin@vghtc.gov.tw

Keywords: nasopharyngeal carcinoma, radiotherapy, plasma Epstein-Barr virus DNA, quantitative polymerase chain reaction Received: October 25, $2015 \quad$ Accepted: April 18, $2016 \quad$ Published: May 12, 2016

\section{ABSTRACT}

Purpose: To investigate the long-term clinical outcome of nasopharyngeal carcinoma (NPC) patients with persistently detectable plasma EBV (pEBV) DNA after curative radiotherapy (RT).

Results: The post-RT pEBV DNA levels were very lower copy number (median 21, interquartile range 8-206 copies/ $\mathrm{ml}$ ). After long-term follow-up, the relapse rate was $64.8 \%$, the median time to progression 20 months, and 5-year overall survival (OS) $49.6 \%$. Thirty-two of $39(82.1 \%$ ) patients with high viral load ( $\geq 100$ copies/ $\mathrm{ml}$ ) developed tumor relapse, whereas $57.0 \%(49 / 86)$ patients with low viral load $(<100$ copies $/ \mathrm{ml})$ had tumor relapse $(P=0.0065)$. The 5 -year OS rates were $20.5 \%$ and $62.9 \%$ for patients with viral load $\geq$ and $<100$ copies $/ \mathrm{ml}$ (median survival, 20 vs. 100 months; $P<0.0001$ ). Patients who received adjuvant chemotherapy (AdjCT) experienced significant reduction in distant failures $(66.2 \% \mathrm{vs} .31 .6 \% ; P=0.0001)$ but similar locoregional recurrences $(P=0.2337)$. The 5 -year OS rates were $69.4 \%$ for patients who received AdjCT compared with $33.2 \%$ for those of without AdjCT (median survival, 111 vs. 32 months; $P<0.0001$ ).

Methods: We screened 931 newly diagnosed NPC patients who finished curative RT and found 125 patients $(13.4 \%)$ with detectable pEBV DNA one week after RT. The clinical characteristics, treatment modality, subsequent failure patterns and survivals were analyzed.

Conclusions: NPC patients with persistently detectable pEBV DNA after curative RT have a higher rate of treatment failure and poor survivals. Levels of the post-RT pEBV DNA and administration of AdjCT affect the final outcome significantly. 


\section{INTRODUCTION}

Nasopharyngeal carcinoma (NPC) has been demonstrated as a radio- and chemo-sensitive tumor. The current standard of care is radiotherapy (RT) alone for early-stage tumor and combined radio-chemotherapy for advanced-stage diseases [1-11]. Treatment failure in the past was due to a high rate of local recurrence and/ or distant metastasis. However, advances in radiation oncology have improved the locoregional control, and treatment failure is now due mainly to distant metastasis.

Many clinicopathological variables were reported to predict treatment outcome. Among them, the TNM staging (extent of local invasion, regional lymphatic spread, and distant metastasis) is the most important prognostic factors in NPC. Recently, cell-free circulating EBV DNA can be detected in plasma and serum of NPC patients, and has been shown as a significant prognosticator at different time-points, including pre-treatment, post-treatment, and middle part of RT [12-22]. Our previous studies found that the post-treatment plasma EBV DNA (pEBV DNA) status (detectable or undetectable) dominated the effect of the pre-treatment viral load and had greater impact than the TNM staging [17-19]. Other investigators confirmed our findings $[20,21]$.

The long-term clinical behavior of NPC patients with persistently detectable pEBV DNA after curative RT with/without chemotherapy has rarely been reported. Thus, we investigate the clinical course in these highrisk patients after long-term follow-up and hope to serve as a reference for future trials of treatment strategy improvement.

\section{RESULTS}

\section{Long-term treatment outcome for 125 patients with detectable pEBV DNA after RT}

No patients were lost to follow. After a median follow-up of 99 months, there were 81 failures and 73 deaths until the time of this writing. The patterns of failures consisted of 9 in local, 6 in regional, 50 in distant, 3 in local + regional, 6 in local + distant, 5 in regional + distant, and 2 in local + regional + distant sites. The relapse rate was $64.8 \%$ and the median time to progression was 20 months. The 1-year, 3-year, and 5 -year LRFFS rates were $93.4 \%, 79.3 \%$, and $72.5 \%$, respectively. The corresponding rates of DMFFS were $68.0 \%, 50.5 \%$, and $49.6 \%$, respectively. The 1 -year, 3 -year, and 5-year rates of OS were $93.6 \%, 60.0 \%$, and $49.5 \%$, respectively.

Patients without persisting pEBV DNA had a significantly lower relapse rate $(172 / 806=21.3 \%)$ and better survivals (5-year LRFFS $=89.2 \%$, 5-year DMFFS $=88.0 \%$, and 5 -year $\mathrm{OS}=85.3 \%$ ).

\section{Effects of the post-RT pEBV DNA viral load on subsequent relapses and survivals}

Table 1 lists the pre-treatment characteristics of the patients according to post-RT viral load. There were no statistically significant differences in terms of age, gender, pathologic type, T-classification, N-classification, overall stage, and modality of initial treatment between the patients with post-RT viral load $\geq$ and $<100$ copies $/ \mathrm{mL}$. Thirty-two of $39(82.1 \%)$ patients with post-RT pEBV DNA $\geq 100$ copies $/ \mathrm{ml}$ developed tumor relapse later, whereas $57.0 \%$ (49/86) patients with post-RT pEBV DNA < 100 copies/ $\mathrm{ml}$ had tumor relapse $(P=0.0065)$. Patients with a lower viral load had significantly less distant failures $(41.9 \%$ vs. $69.2 \% ; P=0.0046$ ) but no difference in locoregional recurrences $(24.4 \%$ vs. $25.6 \% ; P=0.8834)$. The 5 -year DMFFS rates were $30.8 \%$ and $58.2 \%$ for the patients with post-RT viral load $\geq$ and $<100$ copies $/ \mathrm{mL}(P<0.0001$, Figure 1A). The 5-year LRFFS rates for the patients with high and low viral load were $66.5 \%$ and $74.4 \%$, respectively ( $P=0.1841$, Figure 1B). The post-RT viral load affected OS significantly. The 5-year rates of OS were $20.5 \%$ and $62.9 \%$ for the patients with post-RT viral load $\geq$ and $<100$ copies/mL (median survival, 20 vs. 100 months; HR, $0.22 ; 95 \%$ CI, 0.12 to $0.38 ; P<0.0001$, Figure $1 C$ ).

\section{Effects of the post-RT adjuvant chemotherapy on subsequent relapses and survivals}

Table 2 lists the pre-treatment characteristics of the patients according to AdjCT or not. No statistically significant differences in terms of age, gender, pathologic type, T-classification, N-classification, overall stage, and modality of initial treatment between the patients with and without AdjCT were observed. The relapse rates between the patients with and without AdjCT were 54.4\% (31/57) and $73.5 \%(50 / 68)$, respectively $(P=0.0256)$. There were significant reduction in distant failures $(31.6 \%$ vs. $66.2 \%$; $P=0.001)$ but similar locoregional recurrences $(29.8 \%$ vs. $20.6 \% ; P=0.2337$ ) for patients who received AdjCT. The 5-year DMFFS rates for patients with and without AdjCT were $68.7 \%$ and $33.7 \%(P<0.0001$, Figure $2 \mathrm{~A})$, respectively. The 5 -year LRFFS rates were $70.9 \%$ and $74.3 \%$ for the patients who received and did not receive AdjCT ( $P=0.7807$, Figure 2B). The benefits of AdjCT in the reduction of distant metastasis translated into affecting the OS. The 5-year OS rates were $69.4 \%$ for the patients who received AdjCT compared with 33.2\% for those of without AdjCT (median survival, 111 vs. 32 months; HR, 0.38 ; $95 \%$ CI, 0.24 to $0.61 ; P<0.0001$, Figure 2 C).

Six of 39 patients with the high viral load and 51 of 86 patients with the low viral load received AdjCT. Table 3 summarized the survival impacts of AdjCT on both subgroups. AdjCT improved DMFFS $(P=0.0054)$ and OS $(P=0.0137)$ for patients with the low viral load subgroup. Although patients with AdjCT had better 
Table 1: Patient characteristics according to post-RT viral load $(n=125)$

\begin{tabular}{|c|c|c|c|c|c|}
\hline \multirow{3}{*}{ Characteristics } & \multicolumn{4}{|c|}{ pEBV DNA levels } & \multirow{3}{*}{$P$} \\
\hline & \multicolumn{2}{|c|}{$\geq 100$ copies $/ \mathrm{mL}(n=39)$} & \multicolumn{2}{|c|}{$<100$ copies $/ \mathrm{mL}(n=86)$} & \\
\hline & No. & $\%$ & No. & $\%$ & \\
\hline Median age, year & \multicolumn{2}{|c|}{47} & \multicolumn{2}{|c|}{50} & 0.5911 \\
\hline $95 \% \mathrm{CI}$ & \multicolumn{2}{|c|}{$43-51$} & \multicolumn{2}{|c|}{$46-51$} & \\
\hline Sex & & & & & 0.8471 \\
\hline Male & 27 & 69.2 & 61 & 70.9 & \\
\hline Female & 12 & 30.8 & 25 & 29.1 & \\
\hline Pathology (WHO) & & & & & 0.7611 \\
\hline Type I & 0 & 0 & 1 & 1.2 & \\
\hline Type II & 31 & 79.5 & 63 & 73.2 & \\
\hline Type III & 8 & 20.5 & 22 & 25.6 & \\
\hline T-classification & & & & & 0.4742 \\
\hline $\mathrm{T} 1-2$ & 19 & 48.7 & 36 & 41.9 & \\
\hline T3-4 & 20 & 51.3 & 50 & 58.1 & \\
\hline N-classification & & & & & 0.1102 \\
\hline N0-2 & 20 & 51.3 & 57 & 66.3 & \\
\hline N3 & 19 & 48.7 & 29 & 33.7 & \\
\hline Overall stage & & & & & 0.3656 \\
\hline $\mathrm{II}+\mathrm{III}$ & 13 & 33.3 & 36 & 41.9 & \\
\hline IV & 26 & 66.7 & 50 & 58.1 & \\
\hline Previous treatment & & & & & 0.4744 \\
\hline IndCT+RT & 25 & 64.1 & 57 & 66.3 & \\
\hline CCRT & 12 & 30.8 & 26 & 30.2 & \\
\hline IndCT + CCRT & 2 & 5.1 & 1 & 1.2 & \\
\hline RT alone & 0 & 0 & 2 & 2.3 & \\
\hline
\end{tabular}

Abbreviations: IndCT $=$ induction chemotherapy; $\mathrm{RT}=$ radiotherapy; $\mathrm{CCRT}=$ concurrent chemoradiotherapy; $\mathrm{WHO}=$ world health organization.

DMFFS $(P=0.0508)$ and OS $(P=0.3704)$ than those without AdjCT among the high viral load subgroup, the difference did not reach statistical significance.

\section{Factors predicting local control}

Both post-RT viral load $(P=0.6875)$ and AdjCT $(P=0.8391)$ had no significant effects on local failure-free survival for NPC patients with persistently detectable pEBV DNA after curative RT. Conventional T-classification affects local control significantly. The 5-year local failure-free survival rates were $93.4 \%$ for the T1-2 group compared with $74.5 \%$ for the T3-4 group $(P=0.0431)$. In addition, the initial gross target volume (GTV) of the primary tumor positively correlated with the T-classification also affected local control. The 5-year local failure-free survival rates for patients with initial GTV $<$ vs. $\geq$ median value were $91.6 \%$ vs. $75.5 \%(P=0.0541)$, respectively. Tumor response (complete response vs. noncomplete response, $P=0.3540$ ) evaluated $2-3$ months after finishing RT showed no significant impact in predicting local control. 


\section{Cox multivariate analysis}

Variables with $P$ values $<0.10$ in the univariate analysis were incorporated in the multivariate Cox proportional hazards model. After controlling for confounding factors, the effects of post-RT viral load (HR, $0.37 ; 95 \%$ CI, 0.22 to $0.61 ; P<0.001$ ), AdjCT (HR, 0.44; $95 \% \mathrm{CI}, 0.26$ to $0.76 ; P=0.0035$ ), and overall stage (HR, $0.34 ; 95 \% \mathrm{CI}, 0.16$ to $0.69 ; P=0.0029)$ on OS remained statistically significant. Similar results were observed in DMFFS analysis $(P=0.0171$ for post-RT viral load, $P$ $=0.0003$ for AdjCT, and $P=0.0132$ for overall stage). There were no significant independent factors in predicting LRFFS.

\section{DISCUSSION}

NPC has been proven as an EBV-associated cancer for a long time. Recent development of the real-time quantitative polymerase chain reaction assay allows us to detect circulating EBV DNA fragments in most newly diagnosed NPC patients [12-22]. In addition, pEBV DNA was rarely detected in healthy people and long-term survivors of NPC patients without relapse [12, 17]. Many prior studies demonstrate that $\mathrm{pEBV}$ DNA can serve as a reliable biomarker in the detection, monitoring, and prognostic prediction for NPC [12-22].
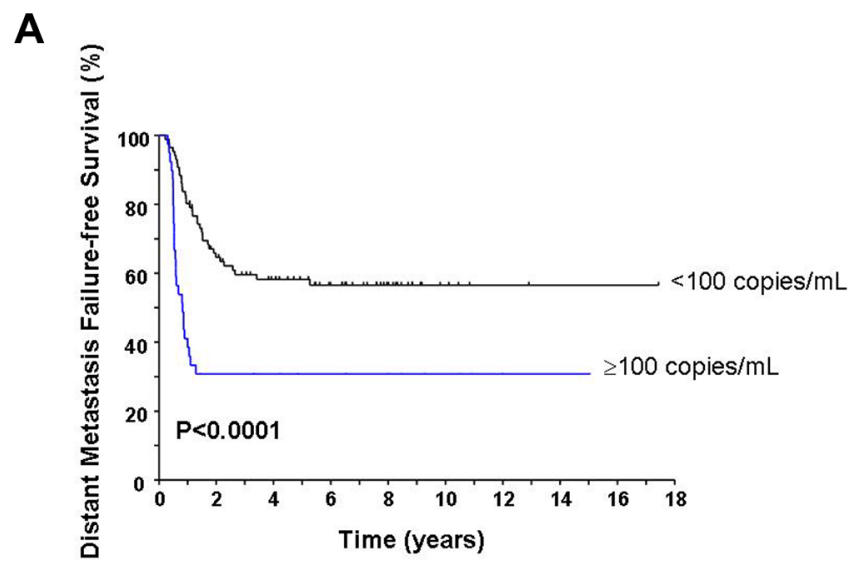

Initially, pre-treatment circulating EBV DNA levels have been shown to correlate with the tumor load, clinical stage, and treatment outcome in NPC. Using a cutoff $>$ or $=0$ copies $/ \mathrm{mL}$, we report for the first time that pEBV DNA levels one week after finishing RT is the most important independent prognostic marker in predicting survivals [17]. In a later study with a minimal of 6 year follow- up and extending sample size, patients with persistently detectable post-RT pEBV DNA had significantly worse OS $(\mathrm{HR}=4.61,95 \% \mathrm{CI}=2.64-7.76$, $P<0.001)$ and relapse-free survival (HR $=7.55,95 \%$ $\mathrm{CI}=4.35-13.12, P<0.001)$ than those with undetectable pEBV DNA [18]. Moreover, the post-RT pEBV DNA status dominated the effect of any other variables, including the pre-treatment pEBV DNA load as well as the TNM staging. Other investigators adopted our cutoff value and showed similar outcome [20,21]. Only one group from Hong Kong used a different cutoff value at post-RT pEBV DNA ( $>500$ copies $/ \mathrm{mL}$ ) that revealed significantly different effects on survival analysis for their patients [14]. However, the Hong Kong NPC Study Group adopted our cutoff value in analyzing 576 NPC patients enrolled in a prospective multicenter trial [23] and confirmed our results. They reported that the 3 -year relapse-free survival $(48.6 \%$ vs. $85.8 \%, P<0.0001)$ and OS $(69.9 \%$ vs. $94.5 \%, P<0.0001)$ were significant worse

B

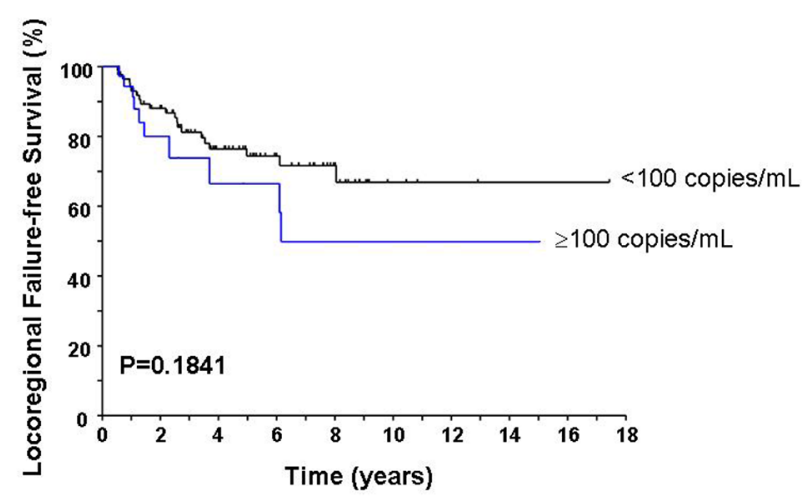

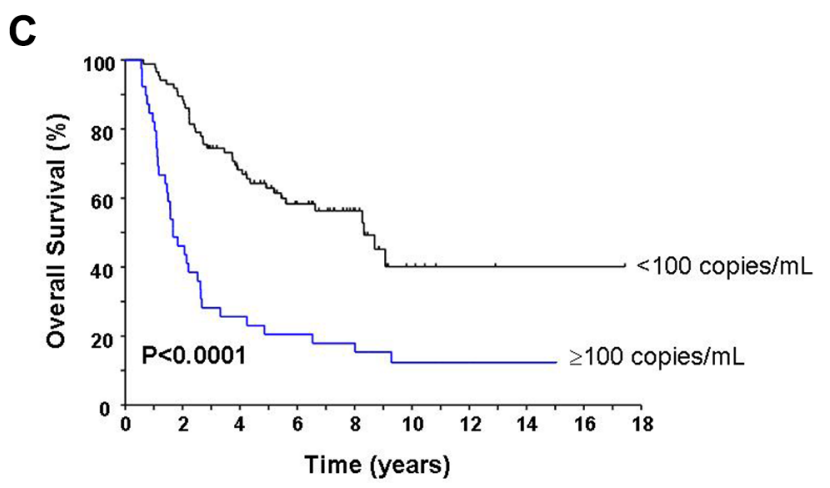

Figure 1: Comparison of the distant metastasis failure-free survival (A), locoregional failure-free survival (B), and overall survival (C) according to the post-RT pEBV DNA load. 
Table 2: Patient characteristics according to post-RT adjuvant chemotherapy $(n=125)$

\begin{tabular}{|c|c|c|c|c|c|}
\hline \multirow{3}{*}{ Characteristics } & \multicolumn{4}{|c|}{ Adjuvant chemotherapy } & \multirow{3}{*}{$P$} \\
\hline & \multicolumn{2}{|c|}{ Yes $(n=57)$} & \multicolumn{2}{|c|}{ No $(n=68)$} & \\
\hline & No. & $\%$ & No. & $\%$ & \\
\hline Median age, year & & & & & 0.7187 \\
\hline $95 \% \mathrm{CI}$ & & & & & \\
\hline Sex & & & & & 0.9598 \\
\hline Male & 40 & 70.2 & 48 & 70.6 & \\
\hline Female & 17 & 29.8 & 20 & 29.4 & \\
\hline Pathology (WHO) & & & & & 0.3427 \\
\hline Type I & 0 & 0 & 1 & 1.5 & \\
\hline Type II & 46 & 80.7 & 48 & 70.6 & \\
\hline Type III & 11 & 19.3 & 19 & 27.9 & \\
\hline T-classification & & & & & 0.7393 \\
\hline T1-2 & 26 & 45.6 & 29 & 42.6 & \\
\hline $\mathrm{T} 3-4$ & 31 & 54.4 & 39 & 57.4 & \\
\hline N-classification & & & & & 0.7430 \\
\hline No-2 & 36 & 63.2 & 41 & 60.3 & \\
\hline N3 & 21 & 36.8 & 27 & 39.7 & \\
\hline Overall stage & & & & & 0.8993 \\
\hline $\mathrm{II}+\mathrm{III}$ & 22 & 38.6 & 27 & 39.7 & \\
\hline IV & 35 & 61.4 & 41 & 60.3 & \\
\hline Previous treatment & & & & & 0.6605 \\
\hline IndCT+RT & 37 & 64.9 & 45 & 66.2 & \\
\hline CCRT & 18 & 31.6 & 20 & 29.4 & \\
\hline IndCT+CCRT & 2 & 3.5 & 1 & 1.5 & \\
\hline RT alone & 0 & 0 & 2 & 2.9 & \\
\hline
\end{tabular}

Abbreviations: $\mathrm{IndCT}=$ induction chemotherapy; $\mathrm{RT}=$ radiotherapy; $\mathrm{CCRT}=$ concurrent chemoradiotherapy; $\mathrm{WHO}=$ world health organization.

for patients with post-RT detectable (>0 copies $/ \mathrm{mL})$ than those with undetectable pEBV DNA after a median follow-up of 3.76 years. An ongoing large randomized trial by the Radiation Therapy Oncology Group (RTOG1315 or NRG-HN001) selected the same cutoff value as ours (post-RT pEBV DNA $>$ or $=0$ copy $/ \mathrm{mL}$ ) to guide further treatment policy. Based on above discussion, we can identify a biomarker-selected high-risk subgroup of NPC patients with persistently detectable post-RT $\mathrm{pEBV}$ DNA. These patients need a more aggressive treatment strategy in future trials.
The current report supplements the data for these biomarker-selected high-risk patients after longterm follow-up. In addition, we further investigate the prognostic impacts of post-RT pEBV DNA concentrations and administration of AdjCT or not in these high-risk patients. Some clinically relevant findings are summarized below. First, only a few (13.4\%) patients experienced persistently detectable $\mathrm{pEBV}$ DNA after RT with/without chemotherapy. Furthermore, the levels of post-RT pEBV DNA (median 21, interquartile range 8-206 copies $/ \mathrm{mL}$ ) for the 125 patients in this study were significantly lower 
Table 3: Effects of AdjCT in patients with high and low viral load after curative RT

\begin{tabular}{|c|c|c|c|c|c|c|c|}
\hline \multirow[b]{2}{*}{ Post-RT plasma EBV DNA } & \multirow[b]{2}{*}{$n$} & \multicolumn{2}{|c|}{ Overall survival } & \multicolumn{2}{|c|}{ DMFFS } & \multicolumn{2}{|c|}{ LRFFS } \\
\hline & & $\begin{array}{c}5 \text {-year rate } \\
(\%)\end{array}$ & $P$ & $\begin{array}{c}5 \text {-year rate } \\
(\%)\end{array}$ & $P$ & $\begin{array}{c}\text { 5-year rate } \\
(\%)\end{array}$ & $P$ \\
\hline High viral load ( $\geq 100$ copies $/ \mathrm{ml}$ ) & 39 & & & & & & \\
\hline AdjCT (Yes) & 6 & 50.0 & 0.3704 & 66.7 & 0.0508 & 66.7 & 0.2332 \\
\hline $\operatorname{AdjCT}(\mathrm{No})$ & 33 & 15.2 & & 24.2 & & 66.1 & \\
\hline Low viral load $(<100$ copies $/ \mathrm{ml})$ & 86 & & & & & & \\
\hline AdjCT (Yes) & 51 & 71.6 & 0.0137 & 69.3 & 0.0054 & 71.5 & 0.8857 \\
\hline $\operatorname{AdjCT}(\mathrm{No})$ & 35 & 50.6 & & 42.5 & & 78.8 & \\
\hline
\end{tabular}

Abbreviations: AdjCT = adjuvant chemotherapy; $\mathrm{RT}=$ radiotherapy; DMFFS = distant metastasis

failure-free survival; LRFFS = locoregional failure-free survival.

compared with those of pre-treatment levels (median 1461, interquartile range $302-4390$ copies $/ \mathrm{mL}$ ) for the 99 patients in our previous study [17]. These data support several established concepts that 1)NPC is a radio- and chemo-sensitive tumor, 2) the current treatment is highly effective for NPC, 3) most tumor cells are eradicated by the radio-chemotherapy, 4) the circulating EBV DNA of most patients drop from a high copy number to undetectable $(0 \mathrm{copy} / \mathrm{mL})$, and 5$)$ only a few patients have detectable but in a very low copy number. Second,
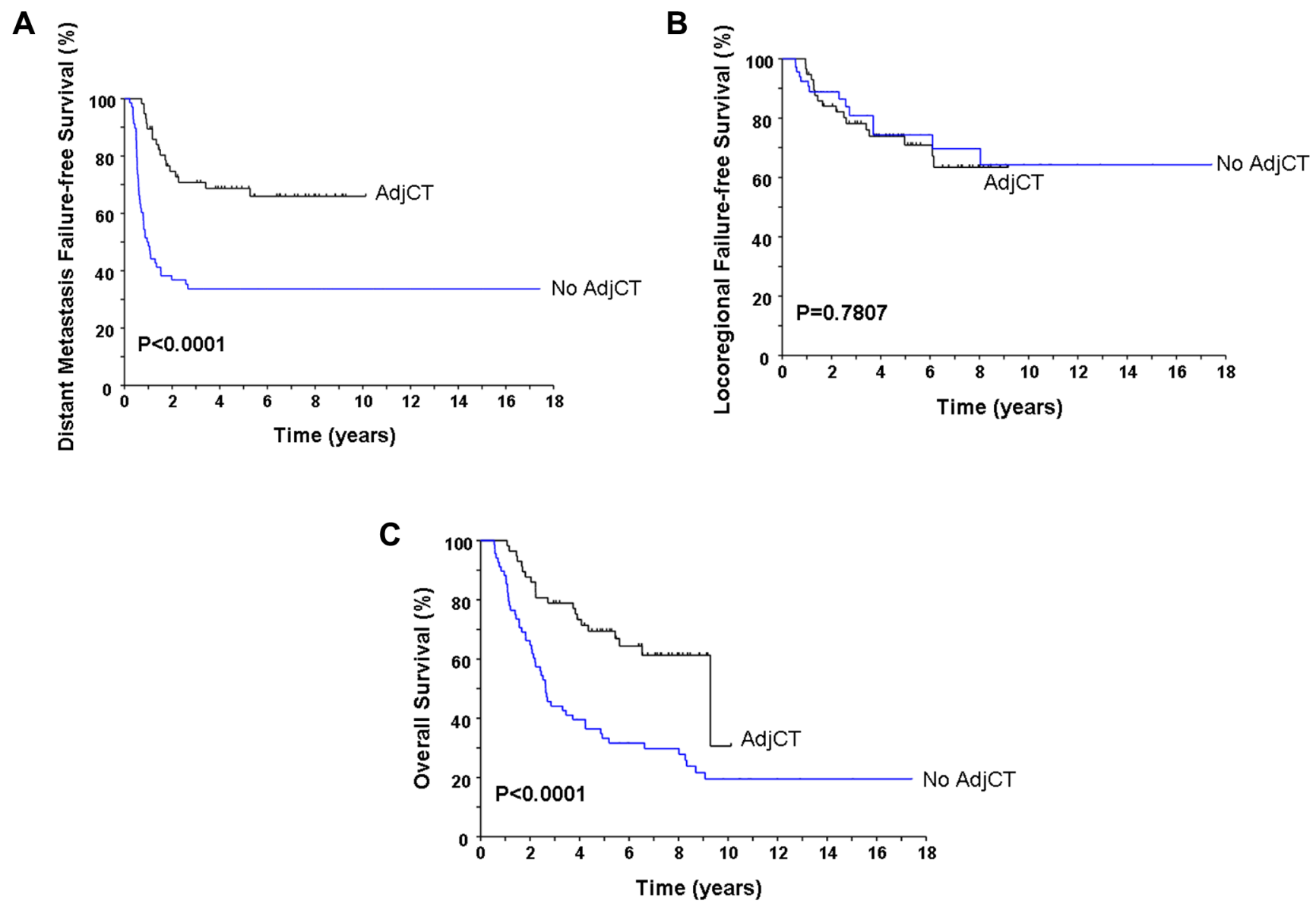

Figure 2: Comparison of the distant metastasis failure-free survival (A), locoregional failure-free survival (B), and overall survival $(C)$ according to the delivery of adjuvant chemotherapy or not. 
the prognostic impacts of the post-RT pEBV DNA levels among these high-risk patients have never been reported. Using an additional cutoff value of 100 copies/ $\mathrm{mL}$, this study showed that patients with a higher viral load ( $\geq 100$ copies $/ \mathrm{mL}$ ) had a worse DMFFS and OS than those with a lower viral load $(<100$ copies $/ \mathrm{mL})$. These findings provide us a new clinical implication that post-RT viral load should be considered as an important stratification factor or the design of different intensive adjuvant therapies for patients with a lower or higher viral load subgroup in future trials. Third, we confirmed our prior study results [24] that adding low-toxic metronomic AdjCT of oral tegafur-uracil with/without cyclophosphamide could reduce distant failure and improve overall survival in NPC patients with persistently detectable pEBV DNA after curative RT by increasing case numbers. Furthermore, subgroup analysis in this study revealed that AdjCT of oral agents benefited for patients with a low viral load but had inadequate benefits for patients with a higher viral load. A second new clinical implication of having another cutoff of 100 copies $/ \mathrm{mL}$ is that adding more intensive adjuvant therapies (intravenous chemotherapeutic or targeted agents) before low-toxic metronomic oral agents should be tried for the high viral load subgroup. Prospective randomized trials are strongly recommended to investigate "what is the best regimen of AdjCT" for different subgroup patients.

The current NCCN guidelines recommend that CCRT using tri-weekly high dose cisplatin followed by AdjCT of PF regimen (cisplatin + 5-fluorouracil) for advanced (stage III-IV) NPC, originated from the results of the Intergroup study (2). However, reports from several previous meta-analyses revealed that no any benefit in using AdjCT for NPC patients [25-28]. These contradictions puzzle most oncologists for decades. A recent update of the meta-analysis actually shows that both CCRT alone and combined CCRT with AdjCT have survival benefits than RT alone [29]. In our opinion, routine delivery of post-RT AdjCT after RT ( \pm induction/ concurrent chemotherapy) for "all" advanced-stage NPC patients should be re-considered. Indeed, patients with advanced disease (stage III-IV) contained a heterogeneous group with variable relapse rate. Pre-treatment prognostic factors (patient's characteristics and initial clinical stages) are no longer important because the tumors in most patients are completely eradicated after initial definitive chemoradiotherapy. This might be one of the reasons why all previous pure AdjCT trial failed to prove its value. We propose that risk-grouping according to postRT characteristics such as post-RT pEBV DNA load, not only according to pre-treatment factors is the key for future AdjCT trials. The ongoing randomized trial (NRGHN001) by the RTOG has selected post-RT pEBV DNA levels $(>$ or $=$ copies $/ \mathrm{mL})$ as the critical-point for different treatment allocation. Patients with undetectable pEBV DNA after CCRT will be randomized to either 3 cycles
AdjCT of PF or close observation. Whereas, patients with persistently detectable pEBV DNA ( $>0$ copies $/ \mathrm{mL}$ ) will be randomized to different AdjCT regimen (PF versus paclitaxel + gemcitabine). Taiwan Cooperative Oncology Group is also performing a phase III randomized trial to compare the outcome between immediate AdjCT (intravenous MEP followed oral tegafur-uracil) and delayed salvage chemotherapy in NPC patients with postRT detectable pEBV DNA.

In summary, only $13.4 \%$ (125/931) patients have persistently detectable circulating EBV DNA but in very low copy number after RT with/without chemotherapy. These subgroup patients have a high subsequent relapse rate $(64.8 \%)$ with predominantly distant failure. The median time to progression is only 20 months and the 5 -year OS rate is $49.5 \%$. Levels of the post-RT pEBV DNA and administration of AdjCT affect the final outcome. Future trials should consider post-RT pEBV DNA levels as a stratification factor and investigate the optimal AdjCT regimen for the target population.

\section{MATERIALS AND METHODS}

The inclusion criteria for this retrospective study were patients with 1) previously untreated, biopsy-proven NPC, 2) no distant metastasis, 3) receiving curative RT with/without chemotherapy, and 4) persistently detectable pEBV DNA one week after RT. A total of 931 patients were screened and 125 patients $(13.4 \%)$ with detectable pEBV DNA after RT were eligible for the final analysis. This study was approved by the Institutional Review Board of our hospital.

There were 88 males and 37 females. The median age was 48 years (range 20 to 82 ). By histology, 124 of 125 patients were identified as having nonkeratinizing carcinoma with differentiated (94 cases, WHO type IIa) or undifferentiated (30 cases, WHO type IIb) type. Only one patient was reported as keratinizing squamous cell carcinoma (WHO type I). The distribution of T-classification and N-classification were $\mathrm{T} 1 / \mathrm{T} 2 / \mathrm{T} 3 /$ $\mathrm{T} 4=18 / 37 / 30 / 40$ and $\mathrm{N} 0 / \mathrm{N} 1 / \mathrm{N} 2 / \mathrm{N} 3=2 / 18 / 57 / 48$ patients. Most patients belong to overall stage IV $(60.8 \%)$. The major modality of initial curative treatment were induction chemotherapy (IndCT) + RT (82 patients, $65.6 \%$ ) and concurrent chemoradiotherapy (CCRT, 38 patients, 30.4\%). Only 3 patients received IndCT + CCRT and 2 patient received RT alone.

Post-RT adjuvant chemotherapy (AdjCT) with oral tegafur-uracil (each capsule contained $100 \mathrm{mg}$ tegafur and $224 \mathrm{mg}$ uracil) 2 capsules twice daily for 12 months was administered for 57 patients. Among them, 24 patients also received oral cyclophosphamide $50 \mathrm{mg}$ per day with tegafur-uracil and intravenous chemotherapy of MEP (mitomycin-C $8 \mathrm{mg} / \mathrm{m}^{2}$, epirubicin $60 \mathrm{mg} / \mathrm{m}^{2}$, and cisplatin $60 \mathrm{mg} / \mathrm{m}^{2}$, repeated every 3 weeks for $4-6$ cycles) were delivered to 5 patients before tegafur-uracil. 
Re-staging survey including computerized tomography (CT) scan or magnetic resonance imaging (MRI) from the skull base to the lower neck, chest $\mathrm{X}$-ray, abdominal sonography and whole-body bone scan were performed 2-3 months after finishing RT. These image studies were repeated once every $6-12$ months during the first 2 years, annually thereafter, and any time when recurrence/metastasis was suspected clinically. ${ }^{18} \mathrm{~F}$-fluorodeoxyglucose positron emission tomography (PET) scan or PET/CT scan was not a routine work-up but was usually done if the above-mentioned examinations were equivocal or physicians in charge wanted to obtain a confirmatory diagnosis and evaluation of the extent of recurrence/metastasis before salvage treatment.

The frequencies of post-RT follow-up are every $1-2$ months in the first year, every 2-3 months in the second and third years, every 3-6 months in the fourth and fifth years, and annually thereafter. Flexible nasopharyngoscopy was performed once per 3-6 months during the follow-up visits. All tumor recurrences/metastases were documented by imaging studies along with pathological verification if the lesions were accessible and patients agreed.

The primary end-points of this study were the patterns of failure and survivals in patients with detectable post-RT $\mathrm{pEBV}$ DNA. The secondary end-points were to investigate the prognostic impact of post-RT viral load and post-RT AdjCT on subsequent relapses and survivals. Analyzed outcomes included various relapse rates, time to progression, overall survival (OS), locoregional failurefree survival (LRFFS), and distant metastasis failure-free survival (DMFFS). OS defined as the duration from the first day of curative treatment to the date of death of any cause or the date of the last follow-up visit. LRFFS was calculated from the first day of curative treatment until the day of first occurrence of local, regional, or both locoregional relapse or until the date of the last follow-up visit. DMFFS was calculated from the first day of curative treatment until the day of distant relapse or the date of the last follow-up. Univariate comparison of survival curves were performed by use of the log-rank test. Cox proportional hazards model was used to estimate the hazard ratios (HR) and 95\% confidence intervals (CI) by univariate and multivariate analyses. All analyses were two-sided and a $P$ value of less than 0.05 was considered statistically significant. Analyses were performed by use of SAS (Version 8.0; SAS Institute, Inc., Cary, NC).

\section{CONFLICTS OF INTEREST}

No potential conflicts of interest were disclosed.

\section{GRANT SUPPORT}

This work was supported by grants from the Ministry of Science and Technology (MOST 103-2314-B-075A-005 -MY3), Taichung Veterans General Hospital (TCVGH-1037104C, 1047107C), Taiwan.

\section{REFERENCES}

1. Cvitkovic E and the International Nasopharynx Cancer Study Group. Preliminary results of a randomized trial comparing neoadjuvant chemotherapy (cisplatin, epirubicin, bleomycin) plus radiotherapy vs. radiotherapy alone in stage IV ( $\geq$ N2, M0) undifferentiated nasopharyngeal carcinoma: a positive effect on progression-free survival. Int J Radiat Oncol Biol Phys. 1996; 35:463-9.

2. Al-Sarraf M, LeBlanc M, Giri PG, Fu KK, Cooper J, Vuong T, Forastiere AA, Adams G, Sakr WA, Schuller DE, Ensley JF. Chemoradiotherapy versus radiotherapy in patients with advanced nasopharyngeal cancer: phase III randomized Intergroup study 0099. J Clin Oncol. 1998; 16:1310-7.

3. Lin JC, Jan JS, Hsu CY, Liang WM, Jiang RS, Wang WY. Phase III study of concurrent chemoradiotherapy versus radiotherapy alone for advanced nasopharyngeal carcinoma: positive effect on overall and progression-free survival. J Clin Oncol. 2003; 21:631-7.

4. Wee J, Tan EH, Tai BC, Wong HB, Leong SS, Tan T, Chua ET, Yang E, Lee KM, Fong KW, Tan HS, Lee KS, Loong S, et al. Randomized trial of radiotherapy versus concurrent chemoradiotherapy followed by adjuvant chemotherapy in patients with American Joint Committee on Cancer/International Union Against Cancer stage III and IV nasopharyngeal cancer of the endemic variety. J Clin Oncol. 2005; 23:6730-8.

5. Zhang L, Zhao C, Peng PJ, Lu LX, Huang PY, Han F, Wu SX. Phase III study comparing standard radiotherapy with or without weekly oxaliplatin in treatment of locoregionally advanced nasopharyngeal carcinoma: preliminary results. J Clin Oncol. 2005; 23:8461-8.

6. Chen Y, Liu MZ, Liang SB, Zong JF, Mao YP, Tang LL, Guo Y, Lin AH, Zeng XF, Ma J. Preliminary results of a prospective randomized trial comparing concurrent chemoradiotherapy plus adjuvant chemotherapy with radiotherapy alone in patients with locoregionally advanced nasopharyngeal carcinoma in endemic regions of China. Int J Radiat Oncol Biol Phys. 2008; 71:1356-64.

7. Hui EP, Ma BB, Leung SF, King AD, Mo F, Kam MK, Yu BK, Chiu SK, Kwan WH, Ho R, Chan I, Ahuja AT, Zee BC, et al. Randomized phase II trial of concurrent cisplatin-radiotherapy with or without neoadjuvant decetaxel and cisplatin in advanced nasopharyngeal carcinoma. J Clin Oncol. 2009; 27:242-9.

8. Lee AW, Tung SY, Chua DT, Ngan RKC, Chappell R, Tung R, Siu L, Ng WT, Sze WK, Au GKH, Law SCK, O'Sullivan B, Yau TK, et al. Randomized trial of radiotherapy plus concurrent-adjuvant chemotherapy vs radiotherapy alone for regionally advanced nasopharyngeal carcinoma. J Natl Cancer Inst. 2010; 102:1188-98.

9. Lee AW, Tung SY, Chan ATC, Chappell R, Fu YT, Lu TX, Tan T, Chua DTT, O'Sullivan B, Tung R, Ng WT, 
Leung TW, Leung SF, et al. A randomized trial on addition of concurrent-adjuvant chemotherapy and/or accelerated fractionation for locally-advanced nasopharyngeal carcinoma. Radiother Oncol. 2011; 98:15-22.

10. Chua DT, Ma J, Sham JS, Mai HQ, Choy DT, Hong MH, Lu TX, Min HQ. Long-term survival after cisplatin-based induction chemotherapy and radiotherapy for nasopharyngeal carcinoma: a pooled data analysis of two phase III trials. J Clin Oncol. 2005; 23:1118-24.

11. Chan ATC, Leung SF, Ngan RK, Teo PM, Lau WH, Kwan WH, Hui EP, Yiu HY, Yeo W, Cheung FY, $\mathrm{Yu} \mathrm{KH}$, Chiu KW, Chan DT, et al. Overall survival after concurrent cisplatin-radiotherapy compared with radiotherapy alone in locoregionally advanced nasopharyngeal carcinoma. J Natl Cancer Inst. 2005; 97:536-9.

12. Lo YM, Chan LY, Lo KW, Leung SF, Zhang J, Chan AT, Lee JC, Hjelm NM, Johnson PJ, Huang DP. Quantitative analysis of cell-free Epstein-Barr virus DNA in plasma of patients with nasopharyngeal carcinoma. Cancer Res. 1999; 59:1188-91.

13. Lo YM, Chan ATC, Chan LY, Leung SF, Lam CW, Huang DP, Johnson PJ. Molecular prognostication of nasopharyngeal carcinoma by quantitative analysis of circulating Epstein-Barr virus DNA. Cancer Res. 2000; 60:6878-81.

14. Chan ATC, Lo YM, Zee B, Chan LY, Ma BB, Leung SF, Mo F, Lai M, Ho S, Huang DP, Johnson PJ. Plasma EpsteinBarr virus DNA and residual disease after radiotherapy for undifferentiated nasopharyngeal carcinoma. J Natl Cancer Inst. 2002; 94:1614-9.

15. Leung SF, Chan ATC, Zee B, Ma BB, Chan LY, Johnson PJ, Lo YM. Pretherapy quantitative measurement of circulating Epstein-Barr virus DNA is predictive of posttherapy distant failure in patients with early-stage nasopharyngeal carcinoma of undifferentiated type. Cancer. 2003; 98:288-91.

16. Leung SF, Zee B, Ma BB, Hui EP, Mo F, Lai M, Chan KC, Chan LY, Kwan W, Lo YM, Chan AT. Plasma EpsteinBarr viral deoxyribonucleic acid quantitation complements tumor-node-metastasis staging prognostication in nasopharyngeal carcinoma. J Clin Oncol. 2006; 24:5414-8.

17. Lin JC, Wang WY, Chen KY, Wei YH, Liang WM, Jan JS, Jiang RS. Quantification of plasma Epstein-Barr virus DNA in patients with advanced nasopharyngeal carcinoma. New Engl J Med. 2004; 350:2461-70.

18. Wang WY, Twu CW, Chen HH, Jiang RS, Wu CT, Liang KL, Shih YT, Chen CC, Lin PJ, Liu YC, Lin JC. Long-term survival analysis of nasopharyngeal carcinoma by plasma Epstein-Barr virus DNA levels. Cancer. 2013; 119:963-70.

19. Lin JC, Wang WY, Liang WM, Chou HY, Jan JS, Jiang RS, Wang JY, Twu CW, Liang KL, Chao J, Shen WC. Longterm prognostic effects of plasma Epstein-Barr Virus DNA by minor groove binder-probe real-time quantitative PCR on nasopharyngeal carcinoma patients receiving concurrent chemoradiotherapy. Int J Radiat Oncol Biol Phys. 2007; 68:1342-8.
20. Hou X, Zhao Chong, Guo Y, Han F, Lu LX, Wu SX, Li S, Huang PY, Huang H, Zhang L. Different clinical significance of pre- and post-treatment plasma Epstein-Barr virus DNA load in nasopharyngeal carcinoma treated with radiotherapy. Clin Oncol. 2011; 23:128-33.

21. Le QT, Jones CD, Yau TK, Shirazi HA, Wong PH, Thomas EN, Patterson BK, Lee AW, Zehnder JL. A comparison study of different PCR assays in measuring circulating plasma Epstein-Barr virus DNA levels in patients with nasopharyngeal carcinoma. Clin Cancer Res. 2005; 11:5700-7.

22. Leung SF, Chan KCA, Ma BB, Hui EP, Mo F, Chow KCK, Leung L, Chu KW, Zee B, Lo YMD, Chan ATC. Plasma Epstein-Barr viral DNA load at midpoint of radiotherapy course predicts outcome in advanced-stage nasopharyngeal carcinoma. Ann Oncol. 2014; 25:1204-8.

23. Hui EP, Ma BBY, Chan KCA, Chan CML, Wong CSC, To KF, Chan AWH, Tung SY, Ng WT, Cheng AC, Lee VHF, Chan SL, Loong HHF, et al. Clinical utility of plasam EpsteinBarr virus DNA and ERCC1 single nucleotide polymorphism in nasopharyngeal carcinoma. Cancer. 2015; 12:1272-9.

24. Twu CW, Wang WY, Chen CC, Liang KL, Jiang RS, Wu CT, Shih YT, Lin PJ, Liu YC, Lin JC. Metronomic adjuvant chemotherapy improves treatment outcome in nasopharyngeal carcinoma patients with post-radiation persistently detectable plasma EBV DNA. Int J Radiat Oncol Biol Phys. 2014; 89:21-9.

25. Huncharek M, Kupelnick B. Combined chemoradiation versus radiation therapy alone in locally advanced nasopharyngeal carcinoma: results of a meta-analysis of 1,528 patients from six randomized trials. Am J Clin Oncol. 2002; 25:219-23.

26. Langendijk JA, Leemans CR, Buter J, Berkhof J, Slotman BJ. The additional value of chemotherapy to radiotherapy in locally advanced nasopharyngeal carcinoma: a meta-analysis of the published literature. J Clin Oncol. 2004; 15:4604-12.

27. Baujat B, Audry H, Bourhis J, Chan AT, Onat H, Chua DT, Kwong DL, Al-Sarraf M, Chi KH, Hareyama M, Leung SF, Thephamongkhol K, Pignon JP; MAC-NPC Collaborative Group. Chemotherapy in locally advanced nasopharyngeal carcinoma: an individual patient data meta-analysis of eight randomized trials and 1753 patients. Int J Radiat Oncol Biol Phys. 2006; 64:47-56.

28. Zhang L, Zhao C, Ghimire B, Hong MH, Liu Q, Zhang Y, Guo Y, Huang YZ, Guan ZZ. The role of concurrent chemoradiotherapy in the treatment of locoregionally advanced nasopharyngeal carcinoma among endemic population: a meta-analysis of the phase III randomized trials. BMC Cancer. 2010; 10:558.

29. Blanchard P, Lee A, Marguet S, Leclercq J, Ng WT, Ma J, Chan ATC, Huang PY, Benhamou E, Zhu G, Chua DTT, Chen Y, Mai HQ, et al. Chemotherapy and radiotherapy in nasopharyngeal carcinoma: an update of the MAC-NPC meta-analysis. Lancet Oncol. 2015; 16:645-55. 